\title{
REVIEW OF THE NATIONAL \\ RESEARCH COUNCIL REPORT "MAJOR FACILITIES FOR \\ MATERIALS RESEARCH AND \\ RELATED DISCIPLINES"
}

\section{Prepared by the \\ Materials Ad Hoc Review Panel}

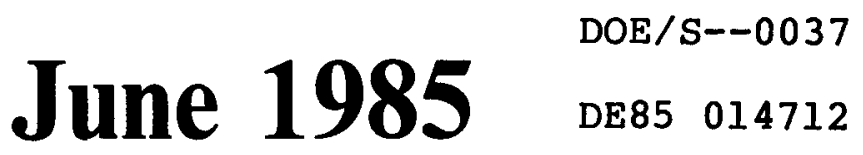

\begin{abstract}
A Report of the
Energy Research Advisory Board to the

United States Department of Energy

Washington, D.C. 20585
\end{abstract}




\section{DISCLAIMER}

This report was prepared as an account of work sponsored by an agency of the United States Government. Neither the United States Government nor any agency Thereof, nor any of their employees, makes any warranty, express or implied, or assumes any legal liability or responsibility for the accuracy, completeness, or usefulness of any information, apparatus, product, or process disclosed, or represents that its use would not infringe privately owned rights. Reference herein to any specific commercial product, process, or service by trade name, trademark, manufacturer, or otherwise does not necessarily constitute or imply its endorsement, recommendation, or favoring by the United States Government or any agency thereof. The views and opinions of authors expressed herein do not necessarily state or reflect those of the United States Government or any agency thereof. 


\section{DISCLAIMER}

Portions of this document may be illegible in electronic image products. Images are produced from the best available original document. 


\section{Energy Research Advisory Board \\ to the \\ United States Department of Energy \\ 1000 Independence Avenue, S.W. \\ Washington D.C. 20585}

(202) 252.8933

The Honorable John S. Herrington

Secretary of Energy

U.S. Department of Energy

1000 Independence Ave., SW

Washington, D.C. 20585

Dear Mr. Secretary:

I am pleased to forward to you the Energy Research Advisory Board's review on "Major Facilities for Materials Research and Related

Disciplines." This review was undertaken in response to Secretary Hodel's request of July 2, 1984 to review four studies being

carried out under the auspices of the National Research Council (NRC) that address the contributions and future potential of various areas of science and engineering. This review is the first such assessment. The others will be done when the relevant NRC studies are completed.

The NRC study on major materials facilities sought to prioritize the various proposed facilities in terms of their importance to science. The ERAB review has undertaken, as requested, to assess the recommended facilities in terms of the Department's programs and responsibilities. Our general finding is that the recommended facilities are needed and will make an important contribution to continuing the nation's scientific and technological leadership. It is al so quite clear that in most instances the Department of Energy is the appropriate locus in the government to address these needs. A phased approach is recommended that would spread the costs over roughly a decade. While we believe that the needed incremental funding should be attainable within the overall flexibility of the Department we do not feel it appropriate for the Board to involve itself in the specifics of the budget. The Board would be concerned, however, if funding levels became so constrained that existing facilities are operated unproductively or individual research projects are curtailed.

It is of particular importance for the major new facilities that a soundly conceived program of pre-construction R\&D be carried out prior to a commitment to build the facility. We believe that such a phase is needed even for the proposed 1-2 GeV synchrotron on which considerable design effort has al ready been expended. This need is underscored by the difficulties that have led the National Science Foundation to terminate efforts to construct a synchrotron facility at the University of Wisconsin. The failure of that project to proceed makes the proposed DOE synchrotron project more urgent. However, it is equally important that the project be carried out with a solid knowledge of cost, schedule and anticipated performance. 
The report also recommends that DOE take the lead in initiating a "shared advisory and decision process" among the agencies that are involved in materials research. In the course of discussing this recommendation it became clear that many ERAB members feel that the government agencies have far too little input from private industry in the formulation of their programs. Therefore, if an advisory structure is established to deal with materials facilities or with materials research more broadly, a strong component of industry participation should be included.

Throughout the course of this review we received assistance and input from DUE Laboratories, other government agencies and staff of the Office of Energy Research, all of whom were cooperative and helpful.

I hope that you will find this report useful and I will be happy to discuss it with you or your staff at your convenience.

Sincerely,

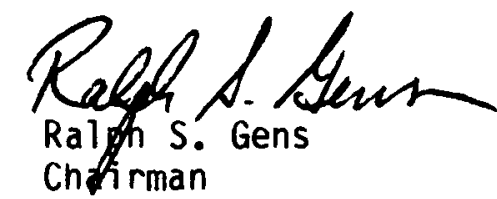




\section{ENERGY RESEARCH ADVISORY BOARD}

Ralph S. Gens, Chairman

Consulting Engineer

Betsy Ancker-Johnson

Vice President

Environmental Activities Staff

General Motors

Frank Baranowski

Consultant

Ivan L. Bennett, Vice Chairman Professor of Medicine

New York University Medical Center

Melvin Calvin

Professor of Chemistry

Department of Chemistry

University of California

William D. Carey

Executive Officer

American Association for the

Advancement of Science

Floyd L. Culler, Jr.

President

Electric Power Research Institute

Gerald L. Decker

President \& Chief Executive Officer

Decker Energy International, Inc.

Mildred Dresselhaus

Professor

Massachusetts Institute of Tech.

Arthur Hansen

Chancellor

Texas A\&M University System

Robert L. Hirsch

Vice President, Exploration \& Production Research

ARCO Gas and 0il Company

Charles J. Hitch

President Emeritus

University of California

John R. Huizenga

Chairman

Department of Chemistry

University of Rochester
John Landis

Senior Vice President

Stone \& Webster Engineering Corpotion

Henry R. Linden

President

Gas Research Institute

William T. McCormick, Jr.

President

American Natural Resources Company

Lawrence T. Papay

Senior Vice President

Southern California Edison Company

Ruth Patrick

Limnology Department

Academy of Natural Sciences

David Pimentel

College of Agriculture

Cornell University

Robert H. Pry

Consultant

Center for Innovative Technology

Eric Reichl

President (Retired)

Conoco Coal Development Company

Louis H. Roddis, Jr.

Consulting Engineer

Francis G. Stehli

Dean, College of Geosciences

University of OKlahoma

Victoria J. Tschinkel

Secretary

Department of Environmental

Regulation

State of Florida

STAFF

Joel A. Snow

Acting Executive Director

Energy Research Advisory Board

Department of Energy 
MEMBERS OF THE AD HOC REVIEW

OF THE NATIONAL RESEARCH COUNCIL REPORT

"MAJOR FACILITIES FOR MATERIALS RESEARCH AND RELATED DISCIPLINES"

*Francis G. Stehli, Chairman
Dean, College of Geosciences
University of Oklahoma
Walter Brown
Head of Radiation Research
AT\&T Bell Laboratories
Richard Claassen
VP, Livermore Programs
Sandia National Laboratories
*John R. Huizenga
Chairman, Dept. Chemistry
University of Rochester
Edward A. Knapp
Research Advisor
Los Alamos Nationai Laboratory

\author{
*Robert H. Pry \\ President \\ Center for Innovative Technology \\ Ralph 0. Simmons \\ Chairman \\ Department of Physics \\ University of Illinois \\ STAFF \\ 'Thomas A. Kitchens \\ Division of Materials Sciences \\ ER-132 \\ US Department of Energy (GTN) \\ Washington, DC 20545 \\ Charles E. Cathey \\ ER-6 \\ Science \& Technology Affiars \\ US Department of Energy \\ Washington, DC 20585
}


COLLEGE OF GEOSCIENCES

OHice of the Dean

60: Elm Sirvel, Room 438

Noman. Oxiahome 73019

(405) 325-3101
April 16, 1985

Mr. Ralpb Geos, Chairmen

Energy Research Advisory Bosrd

4046 S.W. Jerald Court

Portlad, Oregod 97221

Dear Ralph,

In September, you requeated that Arthur Hansen select a oubroup of his panel on Long-Range Researcb to provide an ad boc revieu of the MS Seitz-Eastman Report on Major Facilities for Materials Research and Related Disciplides. This ubgroup was charged to review each recomendation of the Seitr-Eastman Report (hereafter called the S\&E Report) and to recomend an eppropriate DOE action in terws of: 1) DOE programbatic interests, 2) overall importance to the nation, 3) budgeting considerations of cost and tide, and 4) urgeacy of action and overall priorities.

The requested Ad Boc Revieu Camittee vas asembled and coosicted of: Frank Stebli, Chairman; Arthur Hansen; John Buizenga; and Robert Pry (all of ERAB); and, additionally, of Walter Brown, AT\&T Bell Labs; Richard Clasesen, Sandia-liverwore Laboratories; Edward Rapp, LOS Alamos; and Ralph Simons, Univeraity of Illinois. This group bas attempted to examine the nationally oriented S6E Report in terms of events ubsequent to its release and in terms of the DOE aission, including its weaposs aission and to coneider also tbe national oeed for accelerator- and reactor-based aterials researcb facilities wich only DOE can provide. The group also conidered timing, budget and operational matters and makes sone recomendations on these ubjects.

The Review Comittee would appreciate it if the enclosed report could be brought before ERAB at its Hay deeting.

\section{$\mathbf{I G S} / \mathbf{j r}$}

Enclosure

\section{c: Tom Xitchens}

Charlea Catbey

Artbur Bansea

Relpb 6 imonos

Jobn Buizenge

Robert Pry

Edurar Kapp

Walter Brow

nicberd Classen

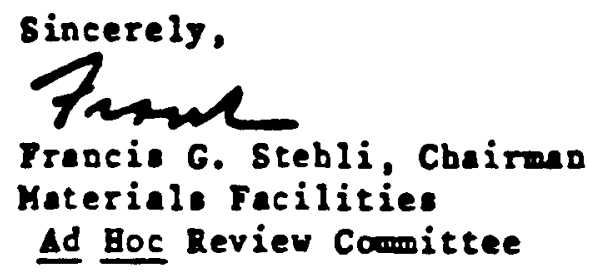

서 Boc Review Comittee 
The National Research Council-National Academy of Sciences report on "Major Facilities for Materials Research and Related Disciplines" recommends that new facilities and upgrades of existing facilities are very important to the nation. At the request of the Secretary of Energy, the Energy Research Advisory Board has reviewed this report and finds that the Department of Energy is responsible for the majority of these projects to carry out its missions in energy, national defense, and science and technology. Therefore, we recommend that the Department should place a high priority on requesting the new funds necessary to fulfill these responsibilities in the next decade. The energy and defense missions of the Department will be best served by this approach. This responsibility requires strong coordination with other funding agencies through a shared advisory and decision-making process.

The review recommends immediate implementation of new capabilities at existing DOE facilities (the neutron experimental halls at Brookhaven and Los Alamos and the new synchrotron insertion devices at Stanford and Brookhaven) as a cost effective way of maintaining the Nation's leading role in neutron scattering and synchrotron radiation research. It also recommends the immediate initiation of non-site-specific research and development for the proposed $6 \mathrm{GeV}$ synchrotron and advanced steady state neutron source. This pre-construction work should be sufficient to ensure that these facilities will be constructed in a timely fashion at design goals and with well identified costs. Other recommendations concern advancing the Nation's leading capabilities in synchrotron produced ultraviolet radiation and spallation neutron research. A budget scenario is developed. 


\section{EXECUTIVE SUMMARY}

Materials are of primary importance in protecting the economic competitiveness of our nation, in efficient and reliable production and use of energy and also in any forseeable new energy and defense technologies. In acknowledgement of this vital role, the Department of Energy and its antecedent organizations, the Energy Research and Development Administration and the Atomic Energy Commission have consistently supported substantial materials research and development programs. The Department currently provides about $\$ 350 \mathrm{milli}$ on annually for materials research and development-making it the largest reported single source of such support in the United States.

Materials research is a broad and diverse group of activities, ranging from concerns with improved mining and minerals processing to fundamental studies of structure and function at the atomic scale. As materials research and development have become more advanced, the associated scientific equipment has become more sophisticated and expensive. Within the last few years, increasing numbers of scientists and engineers involved in materials research and related disciplines have begun to need advanced research facilities such as sources of neutrons, high magnetic field facilities, sources of synchrotron radiation, and special electron microscopes. The Department's laboratories are natural sites for future Major Materials Facilities. Indeed, most of the existing Major Materials Facilities in the U.S. are located at the Department's laboratories and these facilities have commanded an increasing share of the Department's funding for materials research and development.

Due to the diverse capabilities of Major Materials Facilities and the large cost of construction and operations in November 1983, the President's Office of Science and Technology Policy in November 1983 asked the National Research Council to assist in establishing national priorities for future Major Materials Facilities (defined to be those facilities whose initial costs were over $\$ 5$ million). A committee, co-chaired by D. Eastman and F. Seitz, was formed; it included a balanced representation of scientists and engineers in the materials sciences and the related disciplines. The Major Materials Facilities Committee's report and recommendations were submitted to the Office of Science and Technology Policy in July 1984.

In July 1984 the Secretary of Energy requested that the Energy Research Advisory Board review the National Research Council Committee's report, "Major Facilities for Materials Research and Related Disciplines," and recommend an appropriate Department response in terms of:

$$
\begin{aligned}
& \text { - The Department's programmatic interests } \\
& \text { - Importance to the nation } \\
& \text { - Budget considerations of cost and time } \\
& \text { - Urgency of action and overall priorities }
\end{aligned}
$$

This report provides the rationale, analysis and recommendations for the Department's action in response to the Secretary's request. 


\section{A. Findings}

A forefront capability in materials research is vital to our future economic competitiveness and national security. The Major Materials Facilities report has thoroughly examined the anticipated future national needs and opportunities for major materials research facilities and has done an effective job of establishing scientific priorities. We agree with the general conclusion of the Major Materials Facilities Report; namely that, over the next decade, the nation should develop and construct an array of major new facilities and add new capabilities at some existing facilities. This will strengthen the nation's research base in areas that are of vital importance to the nation's future, including energy and security.

We believe that, as indicated in the Major Materials Facilities Report, these needed new investments should not be made in a way that would sap the vitality of other important elements of the materials research enterprise. In particular, support for smaller projects should not be curtailed as a consequence of increased support for existing and new major facilities and existing facilities should be operated productively. Facilities currently under construction should be completed expediently. The fundamental implications of these findings are:

- Significant new investments will be required to equip U.S. science with the modern facilities needed for forefront materials research in the next and future decades.

- Following the priorities outlined in the Major Materials Facilities Report, an overall investment plan is needed that will provide the basis for mutual agreement between the Congress, the Executive Branch, and the scientific community on the pace and sequence of these investments. This plan must be responsive to new ideas and advancements in the rapidly developing technologies associated with the major materials facilities.

- The Department must play the leading role in the development and implementation of this plan due to the responsibilities and capabilities of both the Department and its laboratories. This increase in responsibility must be accompanied with new funds.

These Findings lead to the following general conclusions relevant to the Department's role:

\section{B. General Conclusions}

1. The Department has vital needs for state-of-the-art neutron and photon facilities for materials research and research in related scientific disciplines. These needs reflect the Department's responsibilities for research related to energy and national defense. 
ii. The Department already has a central role in providing such facilities primarily through its national laboratories because of their expertise in the design, construction and operation of large accelerator and reactor facilities for national programs. This central role extends beyond the energy mission of the Department to include the nation's broad science and technology base. Scientists from universities, industry, the Department, and other Federal agencies use and depend upon the Department's facilities. However, this broad role can only be adequately carried out with new funds not only for construction but also for the necessary research and development associated with the construction and operating expenses for the new facilities and capabilities generated.

iii. For the evolution and application of new materials knowledge, the Department and the nation depend on the intellectual efforts of a very diverse cadre of scientists and engineers working in laboratories of all types and sizes. It is essential that the Department continue to strongly support the diverse group. Major new tools for materials research are needed but must be developed and made available with new funds.

iv. To ensure the vitality of the diverse area of materials research and its balance with major materials science facilities, it is essential that the Department's management develop a strategy which explicitly includes the necessary pre-construction research and development, construction, and operations of major facilities and research funding to utilize these facilities. The strategy must involve strong coordination with other funding agencies through a shared advisory and decision-making process.

We want to further stress the essential conclusions above. The facilities and upgrades recommended by the Major Materlals Facilities Report are important to the nation and to the missions of the Department. The Department--and only the Department--can respond to the majority of the recommendations of the Report. We conclude that the Department, in its broad mission to contribute to the nation's science and technology base, should explicity take the major responsibility of providing major new facilities and capabilities for this vital area. The Department should urgently and aggressively seek the necessary new funds to fill these new responsibilities in the next decade. We believe the energy and defense missions of the Department will be best served by this approach. This responsibility for Major Materials Facllities requires strong coordination with other funding agencies through a shared advisory and decision-making process. The remainder of our discussion is based on this broad responsibility.

We conclude that the prerequisites and scientific priorities set down in the Major Materials Facilities Report are consistent with the needs of the Department and are in the best interest of the Nation. The Report has taken a very hard look at all the needs for major facilities and has carefully assigned priorities to the important needs. Our recommendátions for the Department's response related to the specific major facility items in the Report are as listed below. Each recommendation requires immediate and future actions. It is clearly neither feasible nor desirable to fund 
all of the items in the Major Materials Facilities Report simultaneously. Implementation of the Report requires an investment strategy that meets realistic needs on a reasonable timetable and resolves uncertainties without undue exposure to cost escalation and with attention to possible cost savings.

\section{Recommendations}

i. The first three items in the Major Materials Facilities Report having to do with new capabilities at existing facilities should be implemented as quickly as possible. The incremental research value gained for the nation from these additions of moderate expense to the neutron facilities at Los Alamos, Brookhaven, and the National Bureau of Standards and of advanced insertion devices to the photon facilities at Brookhaven, Stanford, and Wisconsin will be extremely cost effective.

- The provision of guide hall facilities and associated instruments for cold neutron research is vital for strengthening neutron beam research in the United States. A start has been made by the President's FY 1986 budget request for such an upgrade at the National Bureau of Standards. The proposed facilities at Brookhaven, which serve research purposes distinct from the upgrade at the Bureau, should be implemented as quickly as possible.

- Adding new insertion devices to existing synchrotron sources at Stanford, Brookhaven and Wisconsin is of major importance to increased capability for national research at these facilities. The research and design of these additional insertion devices should begin now so that construction can follow the new capabilities at synchrotron radiation facilities already included in the FY 1985 and FY 1986 budgets. It is also vital for gaining experience with undulators, a key element in the next generation of synchrotron radiation sources.

- An immediate commitment to construction of the experimental hall and key instrumentation at the Los Alamos facility for spallation neutron research is needed. Until this is accomplished, this important facility cannot function as an effective user-oriented activity. When supported by concurrent developments in target and moderator design and in usable instruments matched to this high flux facility, this relatively modest addition should enable the United States to maintain its leadership in this field.

ii. Both the $6 \mathrm{GeV}$ synchrotron and advanced steady state neutron facilities have the potential to provide order-of-magnitude, or greater, improvements in scientific capability. These two projects have the first and second scientific priorities for new construction in the Major Materials Facilities Report. These are large investments and would provide significant facilities which will operate well into the next century. A program of non-site-specific 
research and development and engineering design should be immediately initiated. Construction commitments should not be made but funding for the pre-construction research and development should be explicitly provided. Th1s should lead to proposals in two to five years for facilities that can be bullt with confidence for successful and timely operations at design goals and well identified costs.

111. There is a recognized need for additional photon facilities in the vacuum ultraviolet both for the overall scientific community and for the research needs of the Department's defense programs. The Major Materials Facilities Report assumed that part of the near term need would be met by the Wisconsin Synchrotron Radiation Center's Aladdin ring, presently under construction. The decision on when the Department should proceed with a 1-2 GeV high brightness synchrotron radiation facility, for which designs exist, must take into account the resolution of difficulties that have arisen with Aladdin subsequent to the Major Materials Facilities Report. If the National Science Foundation decides not to complete and operate Aladdin, the 1-2 GeV synchrotron will be more urgently needed.

iv. The work on enriched pulsed neutron target and moderator assemblies already under development at Argonne should be vigorously pursued and plans should be developed and evaluated to integrate such lowcost enhancements into spallation neutron facilities at Argonne and Los Alamos. These efforts should be followed by research and design studies of a future spallation neutron source capable of peak fluxes in the range of $10^{17}$ neutrons $/ \mathrm{cm}^{2}-\mathrm{sec}$. Decisions on construction of future higher intensity neutron facilities should be based on these studies, the work on the new reactor recommended above, and accumulated international experience obtained with the spallation sources presently going into operation and existing steady state sources.

The National Science Foundation has accepted responsibility for upgrading the National Magnet Laboratory. This is important to the Department because of the need for superconductor research and development associated with accelerator and fusion magnets. As previously noted, the Department of Commerce is seeking funding to provide cold neutron capability at the National Bureau of Standards' reactor. These two steps, if successful, are complementary to the Department's actions recommended above and provide important contributions to the overall scientific capability of the nation. They underscore, however, the multiplicity of Federal efforts in materials research and the need for effective coordination in the advisory and decision-making process. As the principal sponsor of research facilities in this area the Department should take the initiative in establishing such a process. The Major Materials Facilities Report also refers to a need for further panels to address important aspects of materials research other than major materials facilities. We support this statement. 


$$
-6-
$$

A budget scenario is developed. It calls for a gradual increase in the construction budget by about $\$ 6-7$ million per annum for each of 8 years and an increase in the operating budget, for operations, maintenance, and DOE research, of $\$ 7-8$ million per annum for each of the first 3 years. 


\section{BACKGROUND AND CHARGES}

Materials are of primary importance in protecting the economic competitiveness of our nation, in efficient and reliable production and use of energy and also in any forseeable new energy and defense technologies. In acknowledgement of this vital role, the Department of Energy and its antecedent organizations, the Energy Research and Development Administration (ERDA) and the Atomic Energy Commission (AEC), have consistently supported substantial materials research and development programs. The Department currently provides about $\$ 350$ million annually for materials research and development--making it the largest reported single source of such support in the United States. Materials sciences and the associated development efforts are a major area of focus for the Department because the limitations of materials properties constrain extant energy production and conversion systems as well as the development of new alternative energy technologies and defense systems. Because of the vital importance of materials to the nation's long-range economic development, security, energy usage and energy conservation, the Department provides approximately one-third of the funding for research and development in the materials sciences.

Materials research is a broad and diverse group of activities, ranging from concerns with improved alloys and welding processes to fundamental studies of structure and properties of materials on the atomic scale. As materials research and development have become more advanced, the associated scientific equipment has become more sophisticated and expensive. Within the last few years, increasing numbers of scientists and engineers involved in materials research and related disciplines have begun to need advanced research facilities such as sources of high intensity neutron beams, high magnetic field facilities, very intense sources of synchrotron radiation, and special electron microscopes. The DOE laboratories are natural sites for Major Materials Facilities. Indeed, the majority of the existing Major Materials Facilities in the U.S. are located at DOE laboratories: these extant facilities and facilities under construction command an increasing share of the DOE funding for materials research and development.

Recently new major materials facilities as well as several upgrades of existing facilities have been proposed. Operational costs, development schedules and construction periods have increased with the sophistication of these new facilities. To expect all of the proposed construction to be initiated over the next few years is unreasonable. Due to the diverse capabilities of Major Materials Facilities and the increasingly larger costs of construction and operations, the President's Office of Science and Technology Policy (OSTP) in November 1983 asked the National Research Council (NRC) to assist in establishing national priorities for future Major Materials Facilities ( (MMF)--defined to be those facilities whose initial costs were over $\$ 5$ million).

A committee of 22 members was formed within the NRC Commission on Physical Sciences, Mathematics, and Resources, representing the diverse disciplines that use facilities for major materials. The Committee's membership was also intended to mirror the differing research styles and the wide spectrum of organizations where the research is done. Scientific work 
with materials varies from that principally requiring laboratory-scale instrumentation to that dependent on the avallability of major facilities. The research is done by governmental, academic, and industrial scientists and engineers.

The Major Materials Facilities Committee, co-chaired by Dean Eastman and Frederick Seitz, first met late in January 1984 and three times thereafter. The task of studying the diverse MMF proposals was difficult. However, the status of neutron scattering and of synchrotron radiation sources had been reviewed recently by panels of experts for the NRC. A 1979 NRC study on HighMagnetic-Field Research and Facilities and a 1984 DOE planning study for advanced synchrotron radiation facilities were also available. The Report of the MMF Committee and its recommendations were forwarded to Dr. Keyworth late in July 1984 and published by the NRC as "Major Facilities for Materials Research and Related Disciplines" (Ref.1). Appendix A contains the Executive Summary of this report.

In July 1984, the Secretary of Energy requested that the Energy Research Advisory Board (ERAB) undertake ad hoc Reviews of four NRC reports including the one described above (See Appendix $B$ ). He recognized that the recommendations and information in the reports could have a major effect on the Department's science efforts in programs of the Office of Energy Research and also on those of other components of the Department. He requested that the Reviews:

- Examine the substantive recommendations of the reports

- Assess the significance in terms of the Department's programs and responsibilities

- Recommend appropriate action and

- Complete the assessment in six months

Subsequently, Kalph Gens, Chairman of ERAB, asked Arthur Hansen to form a group to review the MMF report (See Appendix $C$ ). He requested that the Review:

- Consider the appropriateness and urgency of DOE implementation of the recommendations

- Set priorities by considering, from the DOE point-of-view, the needs of present and potential users and the overall importance to the nation

- Account for timing, costs and urgency of the various choices in a plan for implementing the Reviews recommendations

- Consider any further needs or requirements which were not fully addressed by the MMF Committee

- Obtain the views of DOE program personnel and of others having interest in such facilities including potential university, industry and national laboratory project personnel and facility users

A Review consisting of four ERAB members and four external members was assembled. A 1ist of the members follows the transmittal letters. The Review began its deliberations with its first meeting, 0ctober $30,1984$. 
III. REVIEW PROCEDURES AND CONSIDERATIONS

The external members of the ad hoc Review were selected to provide broad expertise in the materials sciences and related disciplines but also to represent national laboratories, industrial and academic institutions as well as many regions of the USA. The Review held three publically announced and geographically distributed meetings: the first was held in Washington, D.C. on October 30, 1984, the second in Berkeley, CA, on December 12, 1984, and the last in Chicago, Illinois, on January 25-26, 1985. This provided the opportunity for participation by the public across the nation. Appendix D. contains the agenda of these meetings. An informal final meeting was held in Washington on April 30, 1985, for the purpose of clearing up some remaining questions and finishing the draft report to be presented to the Energy Research Advisory Board on May 2, 1985.

NRC panels and surveys, DOE topical workshops and planning studies and other sources have produced more than a dozen reports which concern the MMF in the last few years. Consequently, much of the information pertinent to the Review was read by the members. See Section VI for the bibliography of reports used in this review. The first meeting was devoted to determining the response other Federal agencies expected to make to the MMF Report. Briefings on the applications of neutron research and synchrotron radiation research were given in the first and the second meetings. Speakers on neutron research and synchrotron radiation research were carefully chosen to be experts but with minimal institutional stock in the MMF Report recommendations. Before the second meeting, all of the DOE Laboratories were polled for their thoughts on the MMF Report recommendations in regard to their mission, their use of the MMF, and on the statistics of operation and use of any MMF located at their laboratory. (These statistics are presented in summary form in Appendix E.) The second, third, and the informal final meetings contained briefings from the DOE laboratories on these questions and their plans involving new MMF. 


\section{FINDINGS, CONCLUSIONS AND RECOMMENDATIONS}

The Review, while responding to the charges outlined in II., organized its thoughts around some managerial issues and the recommendations of the MMF Report. Its findings and recommended DOE actions are presented below. From the outset we w11l assume a famillarity w1th the MMF Report and the information in 1ts references. For easy reference, Appendix A contains the executive summary of the Report. We suggest a careful reading of the first and second major sections, MATERIALS RESEARCH: FACILITIES AND MODES and MAJOR MATERIALS FACILITIES; SCIENCE AND TECHNOLOGY, respectively. They form an excellent and succinct background for the following discussion. Here we w11l provide only information on developments since the writing of the MMF Report and give supplementary information important to the concerns of the Department. We believe our conclusions and recommendations are appropriate for the Department in response to its mission and the nation's needs.

From briefings and other information avallable to us, we find that a forefront capability in materials research is vital for our energy production and usage, our national defense programs, and for a successful economic future which must necessarily be based on 'high technologies'. By the end of our fact-finding meetings, we unanimously agreed on our major conclusion--the prerequisites and scientific priorities set in the MMF Report are generally consistent with the needs of the DOE missions and in the best interest of the nation. The MMF Report is a well-balanced assessment of the national needs and carefully draws its scientific priorities commensurate with these needs. Our next charge was to examine the urgency and sequence of DOE actions and cost scenarios.

We will present our views on the necessary costs to construct the array of major new facilities and new capabilities at existing facilities which have been recommended by the MMF Report and this Review in Section $V$. We find that a significant investment of additional resources will be required to provide the nation's scientists and engineers with the recommended modern facilities for forefront materials research in the next years and into the future decade. A conservative balanced overall plan based on the priorities of the MMF Report is required to secure the mutual agreement and support of Congress, the Executive Branch and the scientific community on the sequence and rate of expenditures. This plan must be responsive to new information and technological innovations as they become available.

The Department is presently responsible for the maintenance and operation of most of the major research facilities in the physical sciences (Ref. 2). This statement also holds for the MMF subset (Ref. 3 and 4). The excellent capabilities of both the Department and the DOE laboratories to administer, develop, and construct major research facilities strongly support the conclusion that the DOE must play a leading role in implementing the overall MMF plan.

During the review, a few observations were made that have apparently not been widely recognized. The first is that the MMF are not of the same 
character as other 'Big Science' facilities. The general mode of utilization is that a user initiates a research program in a home laboratory and uses the MMF when special capabilities unavallable in the home laboratory are needed. In this sense the MMF are not 'large-scale science' but instead play host to many small-scale projects. For example, the National Synchrotron Light Source will support nearly 100 simultaneous experiments when it is fully operational. It is interesting that its operating budget is actually much less than that required to operate enough rotating anode $X$-ray sources to produce the same integrated flux of X-rays, yet its capabilities are far greater due to the special characteristics of its $X$-ray emissions, such as the polarization and the very small divergence. It is, however, important to recognize the vital role of the home laboratory, where much of materials science is developed and young scientists are belng trained. We find that it is essential to maintain the diversity of the home laboratories as the wellspring of research on materials and, just as importantly, the source of young scientists.

It was also noted that support of operations of the extant MMF from the DOE Division of Materials Sciences (DMS) is increasing but leveling off near one-fifth of its budget--a point of concern in reference 5 and, indirectly, in the MMF Report. However, the MMF operations portion of the total national budget for materials research and development and the related disciplines is not more than 5 percent. [We arrive at this number by noting that the DMS budget is only about one-third of the total materials research and development budget in the Department and that the Department's budget is only about one-third of the total national budget for materials research and development. Accounting for the utilization of the MMF by the related disciplines and the MMF supported by other agencies, the portion remains less than 5 percent.] Even large increases, say by 40 percent in the operations costs of the MMF could be balanced in the sense of the first prerequisite of the MMF Report by an additional coordinated 2 percent [ 40 percent of 5 percent] increase in the total national materials research budget. It is important that this small but not insignificant increase be assured by a strong coordination between the Department, other funding agencies, and Congress.

However, the increasing portion of the DOE Division of Materials Sclences budget for MMF is of special concern to the DOE (Ref. 5) and to those supported by that Division. Our poll of the DOE laboratories indicates that those laboratories that host a MMF have suffered reductions in the components of their materials research budgets not specifically associated with the MMFs. This has resulted in a shift of the mission of several laboratories from materials-related research to facility operation. This reduction in DOE materials research is detrimental to the mission of the Department. To maintain the vitality of the DOE materials effort, a budget strategy must be developed which removes this adverse effect. However, we do not advocate the most obvious solution, that MMF construction and support become an independent item in the DOE budget because of the concomitant decrease in flexibility to meet unanticipated needs. 
We also studied the channels of coordination and advice to the DOE Division of Materials Sciences. At the top level, coordination with other federal agencies involved in materials research and development is provided by the Committee on Materials, (COMAT) presently chaired by Dr. J. McTague of OSTP. Strong interagency coordination at the program level for materials science is done through the Interagency Materials Group, a sub-group of COMAT, other interagency committees on special topics, and direct personal contact. Coordination within the Department is accomplished primarily through the Energy Materials Coordinating Committee. The Division of Materials Sciences has a Council on Materials Sciences which provides information on technical emphasis through ad hoc panel meetings and assists the Division in establishing research priorities and user facilities policy. The majority of information about facilities is obtained by the Division through ad hoc expert groups and National Research Council/National Academy of Sciences committees and studies. An example of the latter is the MMF study itself. There are two standing NRC/NAS groups which provide important information to the Division; the National Materials Advisory Board and the Solid State Sciences Committee. The latter of these has organized several studies on specific needs for MMF, a few of which are listed in the references. This plethora of coordination and advisory mechanisms 1llustrates the lack of organizational cohesiveness for the Federal Government's effort in the full field of materials research. Workers in materials science are represented by several professional societies. There is no one body which can speak for even a majority of interests of the materials and materials-related scientists and engineers. We believe the DOE must continue to maintain strong inter- and intradepartment coordination and foster the development of a shared advisory and decision-making process. The process must be developed to at least adequately represent the more basic side of materials research namely, materials science, in the United States: it must be capable of reaching consensus on priorities within the concerned scientific community, the federal agencies, and Congress. The recent move toward joint endeavors by the two groups in the NRC/NAS is laudatory--perhaps the first step toward the goal we have set here.

We found in our meeting with representatives from other federal agencies responsible for funding of materials sciences and the related disciplines which utilize the MMF that they have limited interest in constructing future MMF. It should, however, be noted that the Department of Commerce enthusiastically supports its reactor and the planned upgrade. The Department of Commerce also supports its Synchrotron U1traviolet Radiation Facility (SURF-II) which was not the object of a recommendation of the MMF Report.

The National Science Foundation (NSF) is responsible for the Wisconsin Synchrotron Radiation Center (SRC) with its two rings, the older $240 \mathrm{MeV}$ Tantulus and the $800 \mathrm{MeV}$ Aladdin, which is in a commissioning stage. The NSF is responsible for the Nation's only very high magnetic field facility, the Francis Bitter National Magnet Laboratory at the Massachusetts Institute of Technology, and expects to respond to the MMF recommendations concerning this MMF. The NSF also expressed an interest in the initial site- 
independent exploratory design and development associated with the $6 \mathrm{GeV}$ synchrotron source (see Appendix F). The NSF also supports the Cornell High Energy Synchrotron Source (CHESS), a facility parasitic on the $5.5 \mathrm{GeV}$ Cornell Electron Storage RIng (CESR) facility which was not the object of a recommendation in the MMF report.

There are formal and Informal cooperative programs at the DOE MMF with other countries. The only formal programs are arrangements with the Japanese Atomic Energy Research Institute and the University of Tokyo's Institute of Solid State Physics with Brookhaven and Oak Ridge National Laboratories. Two state-of-the-art neutron spectrometers are being built with Japanese funds in exchange for the use of these and other spectrometers on the High Flux Beam Reactor (BNL) and the High Flux Isotope Reactor (ORNL). Appendix $E$ contains a tabulation illustrating the utilization of these and other DOE user facilities by foreign scientists. The majority of these utilizations are informal and almost always involve long-term basic science in collaboration with American workers. Though we encourage specific international cooperative research and instrument/technique development efforts of the type described above, we do not believe MMF construction or upgrades should be accomplished by international cooperation. The recommendations in this report refer to MMF important to U. S. Industry and, if present DOE policy is followed, are available on a full relmbursement basis for industrial proprietary work. This commercial utilization is increasing and we believe it will continue to increase. Accessibility to state-of-the-art MMF by American industrial concerns improves the nation's international marketplace competitiveness. We believe that international cooperative facilities would inhibit access to U.S. industrial workers and especially for proprietary use if the facilities are not located in North America.

From our poll of the DOE laboratories, we found that they generally strongly supported the MMF Report recommendations in terms of the DOE missions and of each laboratory's own missions.

From these findings we have reached the following general conclusions and recommendations.

A. General Conclusions:

i. The DOE has vital needs for state-of-the-art neutron and photon facilities for materials research and research in related scientific disciplines. These needs reflect DOE mission responsibilities for research related to energy and to national defense.

1i. The DOE already has a central role in providing such facilities, primarily through its national laboratories due to their expertise in the design, construction, and operation of large accelerator and reactor facilities for national programs. This central role extends beyond the energy mission of DOE to include the nation's broad science and technology base. Scientists and engineers from 
universities, industry, the DOE, and other Federal agencies use and depend upon the DOE facilities. However, this extended role can only be adequately carried out with new funds not only for construction but also for the necessary research and development associated with the construction and operating expenses for the new facilities and capabilities generated.

iii. For the evolution and application of new materials knowledge the DOE and the nation depend on the intellectual efforts of a very diverse cadre of scientists and engineers working in laboratories of all types and sizes. It is essential that adequate support of that group in its diversity must remain strong. Major new tools for materials research are needed but must be developed and made available from new funds.

iv. To ensure the vitality of the diverse area of materials research and its balance with major materials science facilities, it is essential that DOE management develop a research strategy which explicitly includes the necessary pre-construction research and development, construction, and operations of major facilities as well as funding for instrumentation and research on the facilities. This strategy must include strong coordination with other funding agencies through a shared advisory and decision-making process.

We want to further stress the essential conclusions by recapitulation. The facilities and upgrades recommended by the Major Materials Facilities Report are important to the nation and to the missions of the Department. The Department--and only the Department--can respond to the majority of the recommendations of the Report. We conclude that the Department, in its broad mission to contribute to the nation's science and technology base, should explicity take the major responsibility of providing major new facilities and capabilities for this vital area. The Department should urgently and aggressively seek the necessary new funds to fill these new responsibilities in the next decade. We believe the energy and defense missions of the Department will be best served by this approach. This responsibility for Major Materials Facilities requires strong coordination with other funding agencies through a shared advisory and decision-making process. The remainder of our discussion is based on this broad responsibility.

The MMF Report details two categories of recommended scientific priorities: major new facilities and upgrades of existing facilities. The Report points out that they complement one another in function, time and required resources. The upgrades are essential to provide the Nation's research needs during the next decade. Planning and designing of new facilities must start now because of the lead time, five to ten or more years, required to construct major new synchrotron radiation and neutron sources. The Report provides a scientific priority list for each category, but not a sequential order of implementation. As we understand from presentations by the authors of the Report, if an item lower on the priority list is undertaken, it should not jeopardize the undertaking of one above it. 
We find the prerequisites and scientific priorities set in the MMF Report consistent with the needs of the Nation and with the needs of the DOE. Below, we recommend a sequence of DOE actions consistent with the scientific priorities of the MMF report, the DOE missions and also events since the writing of the MMF report. Each of our recommendations specifies immediate actions and provides a sequence of actions over the next several years. It is important to note that this report, written less than a year after the MMF report, is being assembled in a time of intense budgetary constraint. It is clearly neither feasible nor technically desirable to fund simultaneously all of the construction discussed in the MMF Report.

\section{B. Recommendations}

i. The first three items in the MMF Report having to do with upgrades of existing facilities should be implemented as quickly as possible. The incremental research value gained from these modest additions to the neutron facilities at LANL, BNL, and NBS and of the advanced insertion devices to the photon facilities at BNL, Stanford, and Wisconsin will be extremely cost effective.

- The provision of guide hall facilities and associated instruments for cold neutron research is vital for the continued health of neutron beam research in the United States.

Funding for the NBS hall is in the President's FY 1986 budget. If this hall were constructed this need would be partially met. However, we realize that the proposed upgrade of the High Flux Beam Reactor (HFBR) at BNL has a different complement of neutron scattering spectrometers and, in addition to its use for materlals research and blological studies using neutrons, the upgrade will satisfy the needs of positron annihilation studies of materials and some in nuclear physics. Further reasons for the priority of this upgrade are given in the MMF Report.

- Adding insertion devices to the existing synchrotron sources is of major importance if we are to increase our capability for national research at these facilities. The research and design of these additional insertion devices should begin now so that construction can follow the new capabilities at synchrotron radiation facilities already included in the FY 1985 and FY 1986 budgets. It is also vital for gaining experience with undulators, a key element in the next generation of synchrotron radiation sources.

Arguments for this item are documented in the MMF Report, reference 7 and reference 8 .

- An immediate commitment to construction of the experimental hall and key instrumentation at the Los Alamos facility for spallation neutron research is needed. When supported by concurrent 
developments in target and moderator design and in usable instruments matched to this high flux facility, this relatively modest expenditure should enable the United States to maintain its leadership in this field.

The Intense Pulsed Neutron Source (IPNS) at ANL is now very heavily oversubscribed. The Los Alamos hall is an integral part of a DOE plan to maintain the nation's lead in spallation sources, a plan based on the research opportunities using pulsed neutrons and epithermal neutrons. This plan called for initiation of construction of the hall at Los Alamos in FY 1984. Its construction had been approved by the DOE. The Proton Storage Ring (PSR), built with funds from the DOE defense programs, will make the facility one of the most intense pulsed sources of neutrons in the world. The PSR is in the final commissioning stage: it should operate within the year. As a result of the workshop on neutron scattering held on Shelter Island, October 1984, (Ref. 6) the potential of spallation neutron sources is now better appreciated. The immediate international competition is manifested in the Spallation Neutron Source in England which has capabilities comparable with those potentially available at Los Alamos. It is also in a commissioning stage. We are losing our clear lead position but could remain competitive with the Los Alamos upgrade if appropriations were made in FY 1987. We emphasize that this competitive stance can be lost unless pulsed neutron techniques are pursued aggressively without interruption of the evolving programs of the user community. It is important for instrument development needs to be appropriately phased over a period of time, and workable criteria and schedules be established for any transfer from ANL to LANL so that the relevant user community is afforded continuous research opportunities.

ii. Both the $6 \mathrm{GeV}$ synchrotron and advanced steady state neutron facilities have the potential to provide order-of-magnitude or more improvements in scientific capability. These are large investments and would provide significant facilities which will operate well into the next century. A program of non-site-specific research and development and engineering design should be immediately initiated. In these two cases there are uncertainties of cost and design that must be resolved. Construction commitments should not be made at this time but funding for the pre-construction research and development should be explicitly provided. This should lead to proposals in two to five years for facilities that can be built with confidence for successful and timely operations at design goals and well identified costs.

These projects have the first ( $6 \mathrm{GeV}$ Synchrotron) and second (advanced steady state reactor) scientific priorities for new construction in the MMF Report. The report provides justification 
for these scientific priorities. The DOE is the only federal agency able to adequately address the task of building these facilities. Such large scale forefront facilities should avoid commissioning and other difficulties if they are well planned. Adequate designs do not now exist. If the $\mathrm{DOE}$ is to be in a position to make a knowledgeable decision on how and when to construct these facilities with completion dates within this century, the pre-construction research and development must begin now. The research and development effort is required to determine costs and define operating capabilities before sites can be selected and construction begun. There are many steps in this sequence that can lead to delays unless DOE proceeds expeditiously. These tasks are too large and important to depend upon the DOE laboratories to absorb the costs of the pre-construction research and development--although substantial design efforts are now underway at several laboratories. Decisions for early construction of lower priority facilities must not interfere with the design and construction of these two top priority facilities.

Workshops on the capabilities needed for the $6 \mathrm{GeV}$ synchrotron have begun. The first was held in Ames, Iowa, in October 1984 (Ref. 9) and a second in Gaithersburg, Maryland, in March 1985. The interested community of scientists is moving rapidly toward defining the desirable characteristics of this machine and interacting with accelerator designers to determine what is feasible. Future workshops are planned in 1985 and 1986 to consider other related subjects such as the insertion devices and beam line instrumentation for this advanced facility.

For over a year, ORNL has had a planning and design effort (about six man-years) on an advanced steady-state neutron source using internal laboratory funds (Ref, 10). Several case designs have been evaluated, a research and development program has been planned, a preliminary cost estimate has been made, and computer programs have been written for evaluating different reactor designs from the thermal hydraulics and structural mechanics viewpoints. Cost/ benefit studies have demonstrated the wisdom of building a new facility rather than modify the existing High-Flux Isotope Reactor. A workshop on instrumentation for this new reactor has been held (Ref. 11) and a workshop on reactor design is being planned.

Again we remind the reader that the major reasons for the high priority each of these two major facilities commands are given in the MMF Report. Recent developments only strengthen these priorities. The picture is sufficiently clear: only a few words are necessary here.

iii. There is a recognized need for additional photon facilities in the Vacuum UltraViolet (VUV) both for the overall scientific community and for research needs of DOE weapons programs. The MMF Report assumed that part of the near-term need would be met by the 
Wisconsin Synchrotron Radiation Center's Aladdin ring, presently under construction. The decision on when DOE should proceed with a 1-2 GeV high brightness synchrotron radiation facility, for which designs exist, must take into account the resolution of difficulties that have arisen with Aladdin subsequent to the MMF Report. If the National Science Foundation decides not to complete and operate Aladdin, the 1-2 GeV synchrotron will be more urgently needed.

In our briefings on synchrotron radiation and by representatives from the laboratories, we found that the scientific argument for the 1-2 GeV and the $6 \mathrm{GeV}$ synchrotron radiation sources were both strong and that both are needed. The $6 \mathrm{GeV}$ ring was given higher scientific priority because it would lead the world in its capabilities and in addition provide VUV radiation while the converse is not true. On the other hand, the VUV ring at the NSLS (BNL) is saturated--at least two 'refugees' from the Aladdin ring have already been accommodated. LLNL and LANL have future needs for a VUV source available for unclassified defense research and possibly classified research (a restricted access area may be required) in the future. Though some defense research can be done on the NSLS VUV ring, the present fully committed condition makes it awkward to expand the effort. The demonstrated need and the avallability of a good preliminary design (with parameters established by a workshop involving the user community (Ref. 12)) should advance the position of a 1-2 GeV source in the DOE action sequence if the Aladdin project were to be cancelled. Some preconstruction research and development, probably a year in duration and a cost of $\$ 2-3$ million, would be necessary to improve the existing design.

If the NSF does decide to complete the Aladdin ring, it is important to recognize that Aladdin is not a substitute for the $1-2 \mathrm{GeV}$ ring. The latter would provide much higher brightness and be optimized for the use of insertion devices. A design has been reviewed by the DOE for this ring.

1v. The work on enriched pulsed neutron targets, and cold and $300 \mathrm{~K}$ moderator assemblies, already under development at Argonne, should be vigorously pursued and plans should be developed and evaluated to integrate such low-cost enhancements into spallation neutron facilities at Argonne and Los Alamos. These efforts should be followed by research and design studies of future spallation neutron sources capable of peak fluxes in the range of 10 neutrons $/ \mathrm{cm}^{2}-\mathrm{sec}$. Decisions on construction of future higher intensity neutron facilities should be based on these studies, the work on the new steady-state reactor recommended above, and accumulated international experience obtained with the spallation sources presently going into operation and existing steady state sources. 
The MMF Report overestimates the cost of the enriched target assemblies. It is important to recognize the new capabilities that spallation sources will have when they are outfitted with enriched targets and new efficient epithermal, ambient and cryogenic moderators. ANL has a new cryogenic moderator in operation which forms a source of intense neutrons as cold as any steady state source. This advance removes the common perception that spallation sources can not produce cold neutrons. Continuing to pursue this approach could lead to an alternate means of achieving a new and advanced cold neutron capability in the same facility with the intense pulsed epithermal and thermal neutron beams for which spallation sources are known.

Though we concur with the MMF Report that future action on construction of a spallation neutron source should depend upon accumulated experience, we believe that this experience will accumulate rapidly due to the strong user program at the ANL IPNS, the British Spallation Neutron Source, which is now being commissioned, and the LANL spallation neutron source as it reaches full capability from the actions recommended above. At the present time the United States has a slight lead in this field. We can remain competitive through careful nourishment and management including the action recommended above, an a strong and continuous instrument development program, and support for the growing user community. At the same time, advantage should be taken, to the extent possible, of the new vigorous European programs in pulsed sources. Pulsed neutron source technology and experience is quickly growing and we are concerned about losing our competitive position. In order that a proper decision can be made in about five years, some research and design must continue on spallation sources to accumulate the necessary expertise for timely exploitation of these new techniques. Our knowledge of the two types of neutron sources should form a sound basis for a coherent plan, to be determined by either the shared advisory and decision process recommended above, or an independent multidisciplinary advisory group convened for that purpose, to meet the long-term neutron beam research needs of the scientific community. This recommendation is consistent with those by the NRC/NAS 1984 Panel on Neutron Scattering (Ref. 13).

The NSF has accepted responsibility for upgrading the National Magnet Laboratory. This is important to DOE because of the need for superconductor research and development associated with accelerator and fusion magnets. As previously noted, the Department of Commerce is seeking funding to provide cold neutron capability at the NBS reactor. These two steps, if successful, are complementary to the DOE actions recommended above and provide important contributions to the overall scientifc capability of the nation. They underscore, however, the multiplicity of Federal efforts in materials research and the need for effective coordination in the advisory and decision process. As the principal sponsor of research facilities in this area, the DOE should take the initiative in establishing such a process. The Major Materials Facilities Report also refers to a need for further panels to address important aspects of materials research other than major materials fcilities: we support this statement. 


\section{FUNDING SCHEDULE}

A significant investment of additional resources will be required to provide the nation's scientists and engineers with the recommended modern facilities for forefront materials research in the next few years and into the future decade. A conservative balanced overall plan based on the priorities of the MMF Report 18 required to secure the mutual agreement and support of Congress, the Executive Branch and the full scientific community involved in the sequence and rate of expenditures.

In order to understand the possible funding schedules associated with our recommendations, we have spoken with the Basic Energy Sclences personnel, studied the DOE Division of Materials Sciences long-range plan (Ref. 14), the MMF Report and information from subsequent workshops (Refs. 6,10 , and 12). Below are some general remarks and an approximate funding schedule. Detailed planning is beyond the capability of this Review and must be done by the Department.

An important facet of MMF planning is accounting for the substantial costs assoclated with a new facility other than the actual construction costs. Before construction of a facility begins, a program of non-sitespecific research and development is necessary. It must be adequate to insure that the facility can be built with confidence for successful and timely operation at design goals and well identified costs. In the past, this pre-construction R\&D has not been sufficient to accomplish these goals. As the sophistication and complexity of the MMF increases, it is much more important to reach these goals. The total estimated cost of this work is about 10 percent of the total construction costs. The importance and costs of this work are too great to expect the prospective landlords of a major facility to absorb them. The R\&D must be explicity budgeted by the Department.

It is equally important to understand that the operation and maintenance costs of a new major facility are large and ongoing. These costs compete for the same budget monies as other research funding, a point addressed in our discussion on the MMF prerequisites above. If a major facility is to be built, operation and maintenance costs sufficient for effective utilization must be an integral component of the planning. Some of these new operating and maintenance expenses must be compensated by reducing expenses at other facilities and by shutting down some older facilities. New facilities, providing better and usually new capabilities, are of ten more expensive to operate and maintain; full compensation can not be expected. Similarly, expenses of research utilizing the new sophisticated facilities will increase over those associated with the older facilities. The MMF Report estimates that these costs are about 10-15 percent of the total construction cost per annum for synchrotron facilities and about 4-6 percent of the total construction cost per annum for neutron facilities. We suspect that these estimates are too low but do not have better estimates. 
Due to the rapidly developing technologies associated with these major facilities and the long pre-construction and construction phases, it is likely that there will be upgrades to newly constructed major facilities. This element can not be planned but should be anticipated. It is not valid to assume that more pre-construction research and development or simple watting will alleviate this possible encumberance; often the technological advance and new scientific opportunities are established during early operation and instrument development. Delaying construction only insures a reduced national capability to meet our economic and technological

competition. The four cost elements are presented in the schematic funding profile for a major facility in Figure 1. The elements are optimistically scheduled in this figure. Proper detailed planning by the DOE should optimize the phasing of the elements for each new facility.

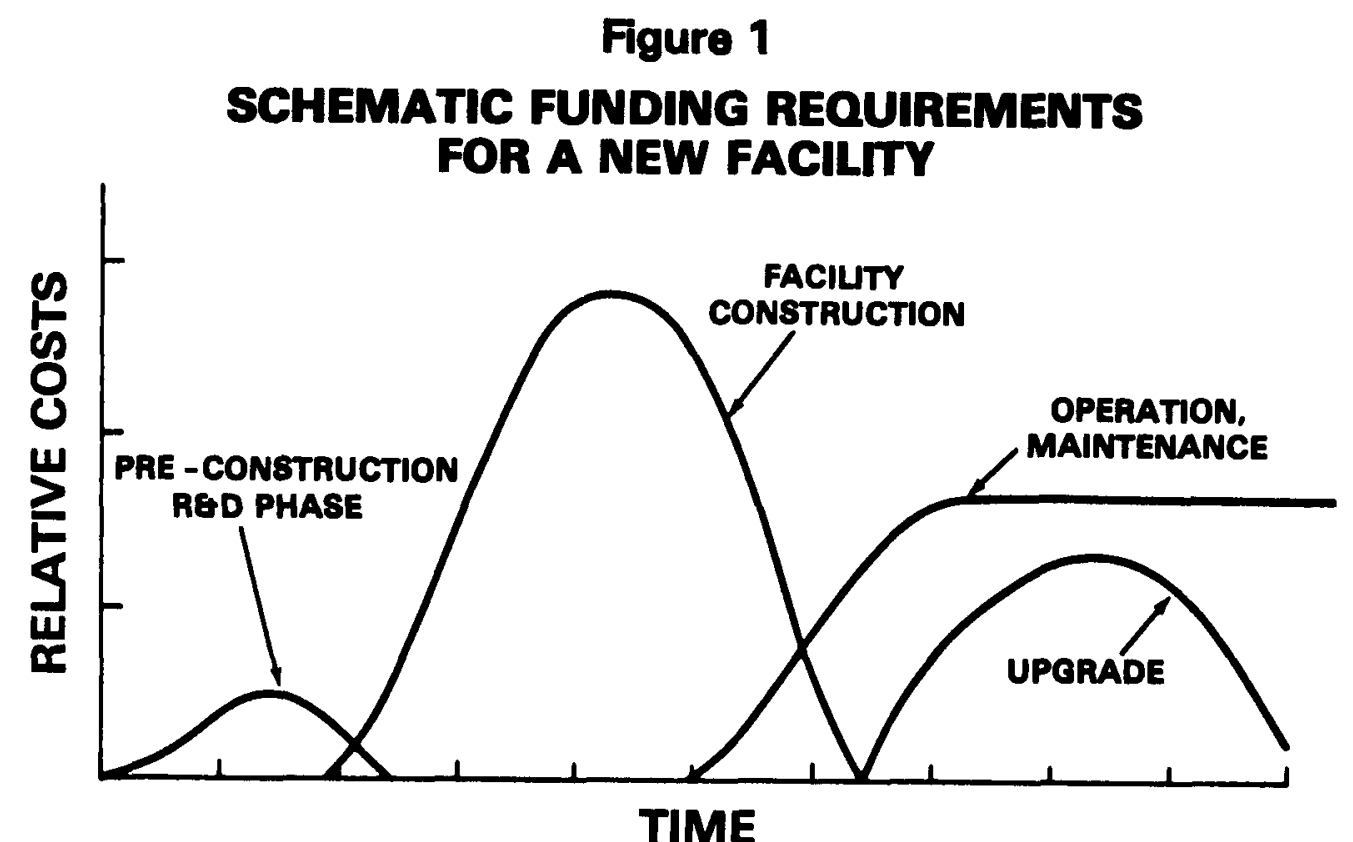

We have recommended immediate funding of three new capabilities at existing facilities. The Department's capability to act on these recommendations depends on its existing commitments (and the process of consensus building by the interested user community in the larger scientific community, the DOE, the Executive Branch and in Congress). Shown in Figure 2 are the existing commitments at the time of the DOE Division of Materials Sciences long-range plan (Ref.14). We conclude that the advanced insertion devices should start in the second year to smooth the financial loads and to allow NSLS Phase II and the improvement underway at Stanford to be completed. 


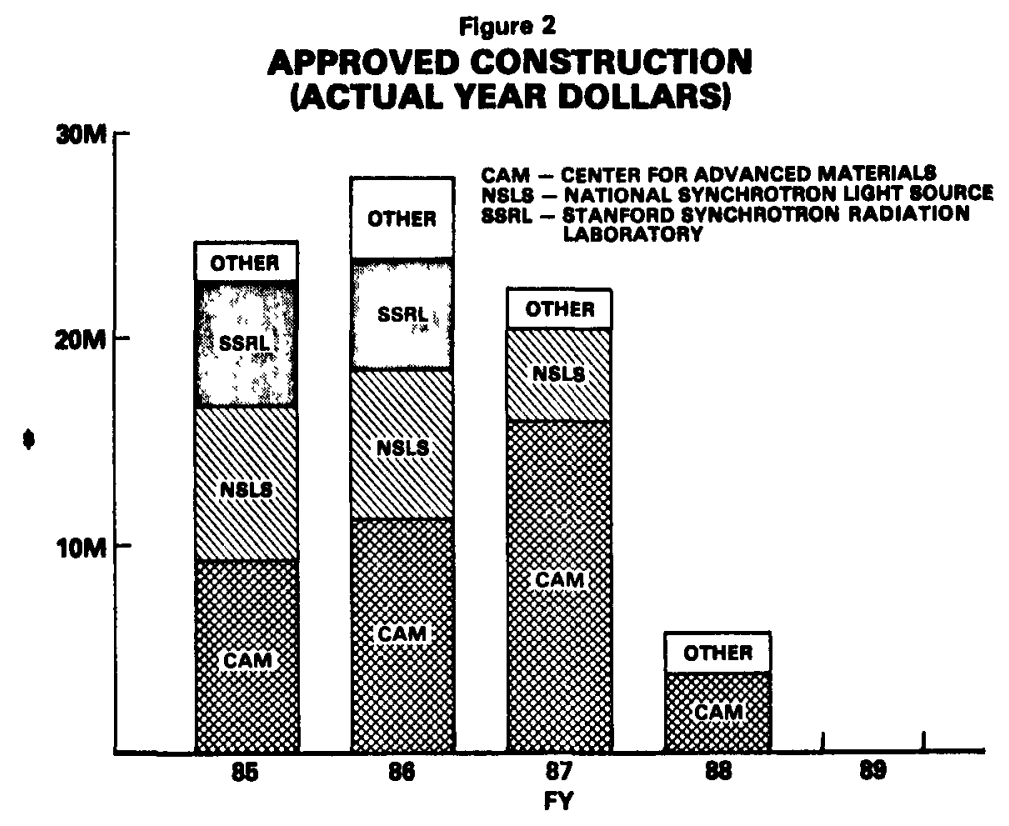

Figure 3 is an adaptation of the long-range plan developed by the DOE Division of Materials Sciences (Ref. 14). Several comments are in order. Estimated construction and operating costs are those given in the MMF Report: we believe that they are underestimated. The boxes do not imply uniform yearly funding but only the total estimated cost and the approximate duration of each phase. We have not included in the figure the addition of new advanced insertion devices at Wisconsin and have estimated about \$16M for such devices at the NSLS (BNL) and SSRL (Stanford). We estimate that the $\$ 30$ million pre-construction research and development for advanced neutron sources should begin at the $\$ 2.5$ million level with about 80 percent going to studies on steady-state sources. Construction projects for the two neutron halls and the 1-2 GeV synchrotron have been previously recommended and have $\mathrm{DOE}$ approved construction plans. Pre-construction research and development and the advanced insertion devices costs should be supported by operating and equipment funds as well as by construction funds.

In conclusion, we find that substantial increases in construction commitments must be made, but a reasonable financial plan for the next decade to accommodate the recommendations is possible. For example, if a plan based on the schedule laid out in Figure 3, is implemented starting in FY 1987, then (1.) an annual real increase (in FY 1985 dollars) of about $\$ 6-7$ million in the DOE Division of Materials Sciences construction budget for each of the first 8 years (over the level in FY 1986), and (2.) an annual real growth (in FY 1985 dollars) of about 6-7 percent, $\$ 7-8$ million, in the Division's operating budget for each of the first 3 years will provide for the additional expenses associated with the new capabilities at existing facilities and with new facilities. This scenario assumes the 1-2 GeV synchrotron source is delayed one year to improve the design with $\$ 2-3$ million of pre-construction research and development expenses. Operating and maintenance costs of the 
three recommended new capabilities are about $\$ 4-5 \mathrm{M}$ per annum. Costs that w1ll arise more than 3 to 5 years in the future are imperfectly known-we believe the MMF estimates, which are used here, are 10-20\% too 10w. Future workshops and pre-construction research and development will be necessary to determine these expenses. A second possible plan which allows an early start to all of the recommended construction is provided in the MMF Report.

We have pointed out above that not all of the facilities needs are within materials sclences. It follows that not all of the new research and instrumentation funding associated with this plan should derive from the DOE Division of Materials Sclences, but the Division's core research budget will need real annual increases of 2-3 percent over the decade to support its share. This provides for the expanded support as well as some of the additional support of smaller scale research programs and instrumentation mandated by the prerequisites in the MMF Report.

\section{Figure 3}

\section{MAJOR MATERIALS FACILTIES PROJECTS (AREAS PROPORTIONAL TO COSTS IN FY 1985 DOLLARS)}

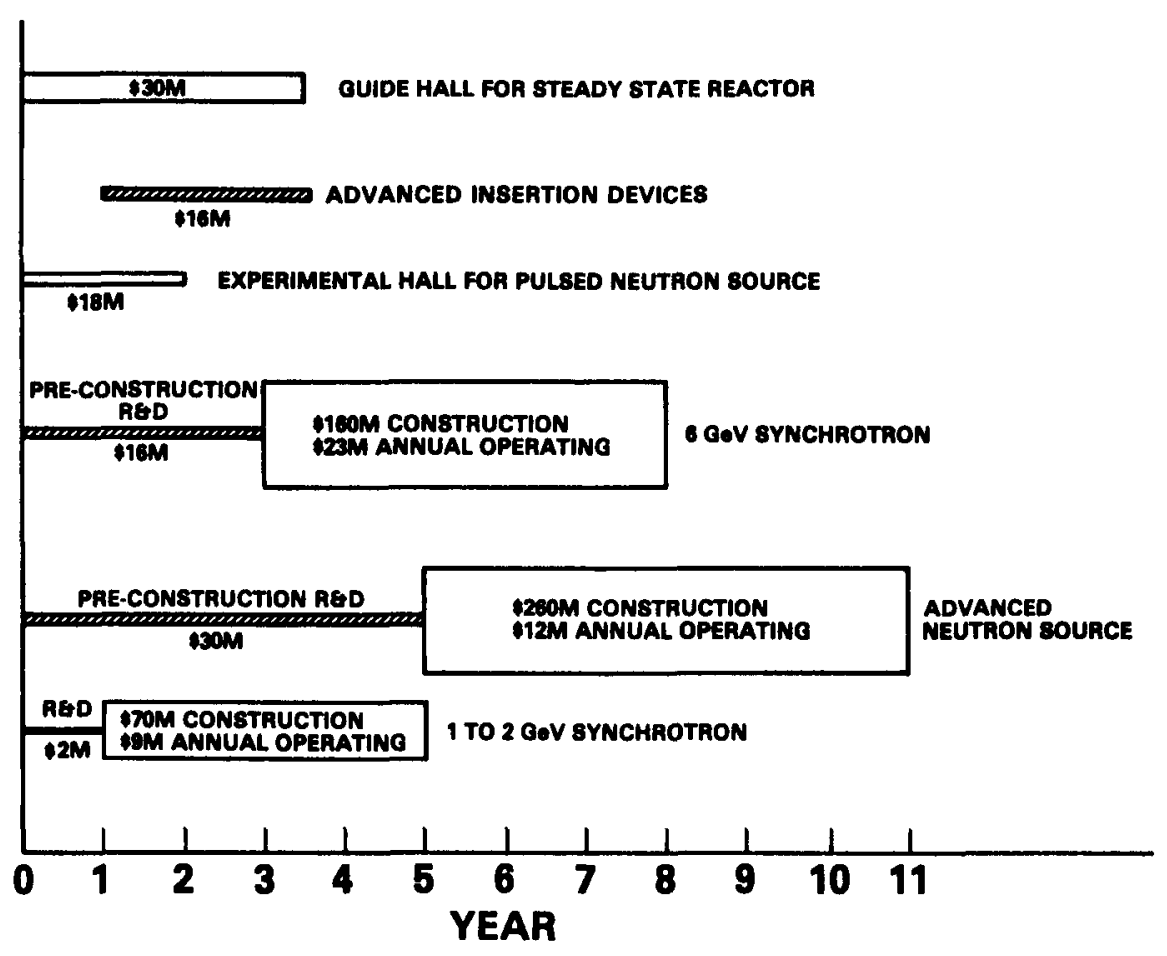




\section{REFERENCES AND BIBLIOGRAPHY}

1. Major Facilities for Materials Research and Related Disciplines, NRC Major Materials Facilities Committee, D. E. Eastman and Frederick Seitz, Co-Chalrmen, National Academy of Sclences, August, 1984.

2. User's Guide to DOE Facilities, DOE/ER-0174, January, 1984.

3. Office of Basic Energy Sciences 1984 Summary Report, DOE/ER-0146/1, November, 1984

4. Materials Sciences Programs $=$ Fiscal Year 1984, DOE/ER-143/2, September 1984.

5. Materials Research and Development, ERAB Materials R\&D Panel, Robert H. Pry, Chairman, DOE/S-0027, November 1983.

6. "Scientific Opportunities with Advanced Facilities for Neutron Scattering", G.H. Lander and V.J. Emery, editors, Shelter Island, NY, October 1984.

7. Current Status of Facilities Dedicated to the Production of Synchrotron Radiation, NRC Solid State Sclences Committee, Subcommittee on Synchrotron Radiation Facilities, D.W. Lynch, Chairman, National Academy of Sciences, Washington, D.C., 1983.

8. Planning Study for Advanced National Synchrotron--Radiation Facilities, National Synchrotron-Radiation Planning Committee, M. Knotek and P. Elsenberger, Co-Chairman, Sandia National Laboratories, Albuquerque, NM, 14 March 1984.

9. Synchrotron Radiation Source Research and Development - Report of a Program Review, D. Lynch and M. Weber, presiders, Ames Laboratory, October 1984.

10. ORNL Presentation to the Major Materials Facilities Committee or the National Research Counc1l, ORNL, D.C. Bartine et a1., February, 1984, and The Center for Neutron Research, Prepared by Oak Ridge National $\overline{\text { Laboratory, }} \overline{\text { March, } 1985 .}$

11. "Proceedings of the Workshop on Instrumentation for the Advanced HighFlux Reactor", R. Moon, editor, Oak Ridge National Laboratory, CONF-8405192, May, 1984.

12. Report on ALS/SSRL User Workshop, A. I. Bienenstock, T. Elioff and G. E. Haller, Co-chairman Lawrence Berkeley Laboratory, Pub. 5095, May 1983. See also National Center for Advanced Materials, Scientific Program Summary, Pub. 5087, Lawrence Berkeley Laboratory, Apri1 1983. 
13. Current Status of Neutron-Scattering Research and Facilities in the United States, NRC Solid State Sciences Committee, Panel on Neutron Scattering, John J. Rush, Chairman, National Academy of Sclences, Washington, DC 1984 .

14. Materials Sciences Division $=$ Long Range P1an, DOE/ER-0212, December 1984.

15. Articles on Neutron Scattering in Physics Today 38 , No.1, January 1985.

16. "Large facilities for condensed-matter science", M. Blume and D. Moncton, Physics Today 38, No.3, March, 1985. 


\author{
Materials Facilities for Materials Research and Related Disciplines \\ NRC Major Materials Facilities Committee \\ D. E. Eastman and Frederick Seitz, Co-Chairman \\ National Academy of Sclences, 1984
}

EXECUTIVE SUMMARY

The science of condensed matter, or materials research, deals with the properties of solids and 1 iquids and their interfaces. It is interdisciplinary, involving materials science, major areas of physics and chemistry, and the earth sciences, biology, and medicine. The understanding of the behavior and properties of materials undergirds every major technology; as a consequence, strength in materials research is essential to national capacities in advanced technology and, hence, to economic competitiveness.

like all sciences, materials research depends on instruments, with these instruments ranging from laboratory ize, such as mass spectrometers, to major national facilities, buch as sources of synchrotron radiation and neutrons.

This report deals solely with major facilities. That was the Comittee's charge. The facilities considered were those that are national in scope, with initial costs on the order of \$5-10 million or more, intended primarily for research on materials. However, materials research done on a laboratory scale is equally vital to the future strength of U.S. materials research. Support for laboratory-8cale science is complementary to, not competitive with, the support for mo jor facilities recomended in this report.

The relatively high costs of major facilities for materials research dictate that priorities be established; and the Comittee in this report recomends priorities for major new facilities and new capabilities at existing facilities, for materials research and related fields. The recomended priorities involve three types of facilities, providing synchrotron radiation, neutrons, and high magnetic fields.

Synchrotron radiation, produced when energetic electrons are deflected by magnetic field, provides over a broad spectral range the most intense source of photons now available. Such radiation can be intensified further by orders of magnitude by using insertion devices-wigs lers and undulators--that put a series of sharp bends in the electron trajectories. Syachrotron-produced photons intersct stongly with atomic electrons, thus, offering means of probing the details of the electronic structure of materials.

In contrast, neutrons, which are produced by nuclear reactions, interact most strongly with atomic nucleii. Neutrons are thus uniquely 
suited to the etudy of lattice dyamics and molecular configurations. In addition, ince the neutron has magnetic moment, neutron scattering offers a unique means of probing the magnetic properties of materials. The most effective use cold neutrons, which have very low velocities, requires that they be transported through opecial tubes, whose walls reflect those neutrons with minimum loss, to large experimental areas called guide halls.

High magnetic fields are essential to the study of a variety of technical and fundamental problems. In particular, high magnetic field facilities are essential to the development of improved superconductors and, in turn, make it possible to construct more efficient superconducting magnets capable of achieving still higher fields.

The Comittee applied the following criteria in establishing its priorities:

- The importance of each facility for frontier research in materials, and consideration of research needs of other fields, including biology, chemistry, atomic and molecular physics, plasma physics, earth science, and medical science.

- The importance of each facility for applied research in areas of national priority; that is, economic competitiveness and security.

- The availability of other, less costly alternatives for accomplishing comparable scientific, technological, and educational goals.

- The contribution of each facility to a long-term national plan for such facilities, including considerations such as capital investment, operations costs, and technical feasibility.

Additional criteria that should be considered in evaluating proposals for new facilities include:

- Technical and scientific resources at the laboratory or university site, including schools or departments in related areas.

- Access and ease of use by extramural academic, industrial, or government laboratory investigators.

- Role of the facility relative to a new or strengthened mission of its home laboratory or university.

- Potential of each facility for training scientists and engineers.

Further, new facilities to be fully effective must be dedicated, that is, used exclusively for synchrotron radiation or neutron based 
research. Finally, to serve the entire conmunity optimally, the geographic distribution of facilities should generally be taken into account.

\section{CONCLUSIONS AND RECOMMENDATIONS}

The Comittee's recommended priorities for major facilities--both new facilities and new capabilities at existing ones--embody two prerequisites :

- That they are accompanied by expanded support of smaller materials research programs, including related instrumentation. Research on this scale continues to provide much of the fundamental new science in the field and to train a large fraction of our scientific and technical manpower.

- That resources must be provided to operate existing user facilities productively. In addition, the approved enhancements of major sypchrotron radiation facilities at the Brookhaven National Laboratory, Stanford University, and the University of Wisconsin should be completed expeditiously, since it will require several years to more than a decade before the new facilities recommended in this report can contribute to the research effort of the United States.

\section{RECOMMENDED PRIORITIES}

The Comittee's recomended priorities for the development and construction of facilities during the next decade include two categories:

- Major new facilities, and

- New capabilities at existing facilities.

These categories complement one another in function, time scale, and required resources. New capabilities at existing facilities are essential for scientific and technological needs in the next decade, while the long lead times needed to construct major new aychrotron radiation and neutron facilities require that we start now with the planning and design of such new facilities. They also require that we begin imediately to implement new capabilities at existing facilities. The Comittee concludes that both categories are essential for the effective evolution of science and advanced technology in the United Stater in the next decade and beyond.

The Committee a 100 recommends the convening of additional panels to address other important aspects of materials research. 
Major New Fac1l1t1es

The Comittee's recomendations for the construction of major new facilities are listed below in order of priorlty.

1. A $6 \mathrm{GeV}$ Synchrotron Radiation Fac111ty. Th1s would be designed to make optimum use of the new scientific and technological opportunities presented by insertion devices. These devices, by providing radiation having orders of magnitude greater brightness than currently avallable, will make it possible to expand on the seminal research using synchrotron radiation carried out in the past decade. A synchrotron radiation facility with a storage ring energy of about $6 \mathrm{GeV}$ will offer both identifiable and unforseeable new opportunities for research throughout the electromagnet1c spectrum. It is cptisal for providing radiation from undulators $a t z^{2}$ it lo $\mathrm{keV}$, where II $s t$ $x$-ray research is done. For example, the brightness increase w11l make it possible to investigate the properties of more complex materials and smaller samples with increased spatial and energy resolution. SiteIndependent design should begin immediately, and the site selection and construction should comence as soon as possible. If construction were. to begin, for example, in FY 87, operation is possible by FY 92.

2. An Advanced Steady State Neutron Fac1lity. The goal is to achieve about ten times the flux of existing machines with a minimum requirement of five times the flux. There are two principal reasons $\mathrm{fc}^{-}$this recomme: dation. First, and most important, a high-flux source ca be designed to optimize beam geometry and flux distribution, so as to yleld greatly increased intensities for all experiments. An increase of about ten times the flux of existing machines is an aggressive but technologically feasible goal. Such a facillty would ensure the United States a leading position in this field. This is especially Important in the cold neutron range, where flux Increases of an order of magnitude can be achieved, providing new capability, for example, for high-resolution spectroscopy and small-angle scattering studies. Second, new source will be a timely replacement for one or more of our existing sources built in the 1960's. Site-independent design should begin 1mmedlately. However, because of safety requirements, the Comittee does not expect construction to begin unt1l about FY 89 with completion possibly by FY 96 .

3. A 1 to $2 \mathrm{GeV}$ Synchrotron Radiation Fac1l1ty. This facility would be centered around Insertion devices but optimized for the vacuum ultraviolet (VUV) and soft x-ray reglon. This facility furnishes addtional sclentific and technical opportunitles for research in chemical physics, electron spectroscopy, and imaging techniques such as microscopy and holography.

4. A High-Intensity Pulsed Neutron Fac1lity. Pulsed neutron sources offer new sclentific capabilitles, especialiy for Investigatlons reguirlng higher energy, or greater than thermal, neutrons. Also, there are practical limits to the intensity that steady state reactors can provide. Thus, future 1mprovements in neutron sources, beyond the second priority above, will probably come from alternative approaches, the most promising of which is based on pulsed neutron 
sources. However, future action $p 9$ the construction of a high Intensity pulsed source (about $10^{17}$ neutrons $/ \mathrm{cm}^{2}-8 e c$ peak flux) should be based upon the results obtalned with lower-intensity pulsed sources.

New Capabilities at Existing Fac1lities

Recent developments make it both practical and cost effective to adapt certaln existing user facilities to new purposes by adding experimental halls, instruments, and modifled sources. These additions provide an opportunity for new frontier sclence; they are not simply extensions of existing work.

The Comittee's recommendations in order of priority for the addition of these new capabilities at existing user facllities are:

1. Centers for Cold Neutron Research. Guide halls and Instrumentation for explo1ting the only cold neutron sources in the U.S. located at the Brookhaven Natlonal Laboratory and at the National Bureau of Standards, should be developed in an orderly fashion.

There is no cold neutron gulde hall in the United States, and such faclitiles are urgently needed to address the rapid expansion of neutron applications in materlals sclence, chemistry, and blology. Many central problems in these sclences can only be solved using new Instruments with cold neutron beams. These centers will enable U.S. scientists to be competitive in cold neutron research during the next decade; and they w111 provide new instrumentation concepts for developing future neutron scattering sources.

2. Insertion Devices on Ex1st1ng Synchrotron Radiation Fac111tles. Insertion devices should be developed in an orderly fashion to exploit about $81 x$ of the remalning stralght sections of existing storage rings. The special characteristics of undulators as radiation sources should be emphasized, to use our existing capability most effectively.

Undulators on existing machines will be our premler synchrotron radiation source for the next 5 years. They w1ll also provide valuable experience for the next generation of synchrotron radiation factlities which will also be based upon undulators. The construction of additlonal insertion devices, when approved, should follow the construction of new capabilities at synchrotron radiation facilities already included in the budgets for FY 85 and FY 86 .

3. Experimental Hall and Instrumentation at the Los Alamos National Laboratory. An experimental hall and new instruments at the pulsed neutron source at the Los Alamos National Laboratory (LANL) would make the United States competitive in pulsed neutron research and would help gulde the development of future pulsed sources.

The expected flux Increase at this facility is an important opportunity to explore, at modest cost, the great promise of pulsed neutron sclence for spectroscoplc and structural problems. 
4. Upgrading of the National Magnet Laboratory. The need for timely development of pulsed magnetic fleld faclities and instrumentation enhancements at the National Magnet Laboratory has been demonstrated. This laboratory, the only major high magnetic field research facility in the United States provides a unique combination of high flelds and low temperatures. Many advances in research depend on its continued development as a dedicated user facility.

5. Enriched Pulsed Neutron Targets. Enriched targets, by exploiting fission events to amplify the neutron flux, can more than double the avallable flux. The development and installation of enriched targets for use at pulsed neutron facllitles would be cost effective.

Prloritles 1 and 2 for major new facllities, when they are 1mplemented, would serve as a centerplece of inis rutio:.'s furure capabllity for synchrotron radiation and neutron based research. Thus, design and siting studies for a $6 \mathrm{GeV}$ synchrotron radiation facility and for an advanced steady state neutron facility should begin Imediately.

Because of the long lead time assoclated with an advanced steady state neutron fac1lity, the 1mmediate 1mplementation of at least one instrumented cold neutron guide hall is necessary to provide forefront capab111ty.

The basis for these conclusions is expanded upon in the body of the report. Chafit: I outlines the characteristics of materials research at universities, at governmental and private laboratories, and in Industry, including research styles, research organizational modes, instrumentation, and the role of national facilities. It also offers a brief summary of the status of U.S. faclilities vis-a-vis those of other countries. Chapter II outlines scientific and technological accomplishments, using major materials facilities, and suggests the likely direction of future research. It presents the scientific and technological rationale for the recomendations in this report. The Comittee's conclusions and recomended priorities for national facilities for materials research and related flelds are given in Chapter III.

The Committee again emphasizes that, in response to its charge, its recomended priorities include only synchrotron radiation, neutron scattering, and high magnetic fleld facilities. Other meritorlous materials research facilities were also discussed by the Comoftee. A number of these are briefly described in Chapters I and III. 
APPENDIX B

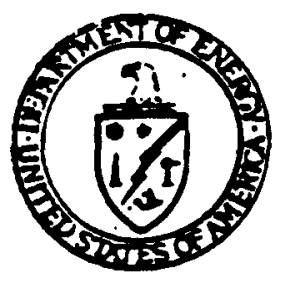

THE SECRETARY OF ENERGY

WASHINGTON. O.C. 20545

July 2, 1984

Mr. Ralph S. Gens

Chaiman

Energy Research Advisory Board

4046 SW. Jerald Court

Portland, OR 97221

Dear Mr. Gens:

The Department of Energy is one of the principal agencies of Government responsible for the support of scientific research, particulariy basic research. Such research is vital to the Nation's long-range economic development and provides the intel lectual underpinning for future technological development.

Four studies are presently being undertaken by the National Research Council (NRC) that have the general objective of describing the contributions and future potential of major materials facilities, chemistry, physics, and engineering. Each of these studies is a major undertaking, involving the participation and effort of large numbers of individuals from their respective scientific comunities. These studies have been undertaken with the cooperation and support of the Office of Science and Technology Policy, this Department, and of other agencies of Government.

It is likely that these studies will provide advice and information that could have a major effect on the Department's science efforts over the coming years. Each area being studied concerns not only the programs of the Office of Energy Research, but also all of the other components of the Department that carry out, research in the areas involved. For this reason, it would be desirable for. the Energy Research Advisory Board to undertake a broadly-based review of each study as it is completed. Such a review would examine the substantive recomendations that have been made, assess their significance in terms of the Department's programs and responsibilities, and recomend to me such action as may be appropriate. These reviews would be of great assistance to the Department and would be consistent with the view, prevfousiy expressed by the Board, that studies of our basic sciences programs are needed. 


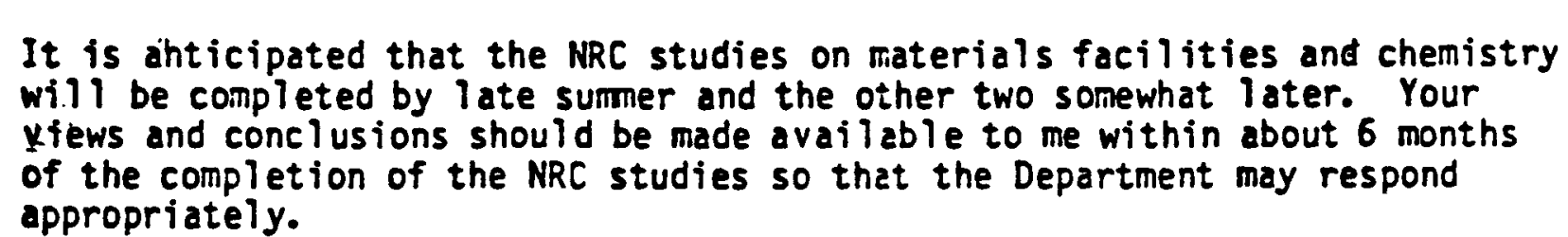

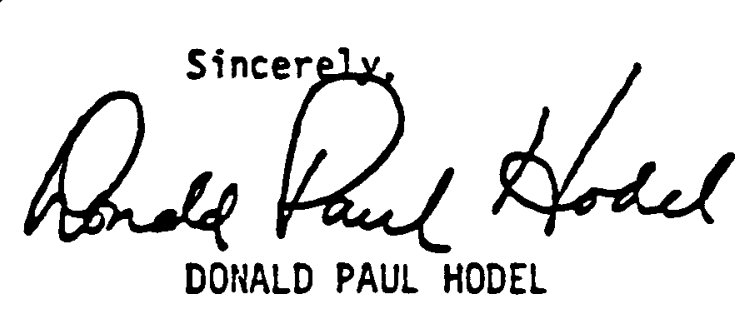


Dr. Arthur Hansen

Chancellor

Texas A\&M University System

College Station, TX 77843

Dear Art,

As we discussed at the Los Alamos meeting, the Secretary has asked ERAB to review for the Department a series of forthcoming National Research Council reports on studies of major scientific disciplines. Given the role of your subpanel in the long-range R\&D strategy study, it seems appropriate for these reviews to be undertaken under your overall direction. The information provided by these reports can then be readily incorporated in your broader deliberations.

There will probably be four such ad hoc reviews to undertake over the next year. I recognize that reviewing these in sequence is somewhat awkward, but waiting until all the studies are in hand would introduce undue delays in DOE's decision processes. When all the reviews are completed, it will then be possible to consider priorities between the various fields.

The first report to be examined is "Major Facilities for Materials and Related Disciplines" that was presented to us at Los Alamos by Dr. Frederick Seitz. That study is of particular importance since DOE provides most of the large national user facilities such as those discussed in the report. The NRC study represents the considered judgment of the scientific community on priority needs for these major facilities. Your review should consider the appropriateness and urgency of DOE implementing any of these recommendations. Each of the recommended facility upgrades and new facilities serves a somewhat different set of needs and potential users. Priorities from the DOE standpoint should consider those differences and the overall importance to the Nation. Implementation of the recommendations in this report must, in addition, take into account the timing, cost, and urgency of the various choices, and whether there are further needs or requirements that were not fully considered.

To carry out the review, I suggest selecting a subgroup from your panel, suitably augmented and balanced with outside experts knowledgeable in the DOE mission areas, and chaired by yourself or another ERAB member. This group might then be briefed by the appropriate DOE program personnel on plans in this area. It should also seek the views of others having an interest in such facilities including potential university, industry, and national laboratory project personnel or facility users.

It would be desirable to have an initial reaction from the group in time for discussion at the ERAB meeting in February 1985.

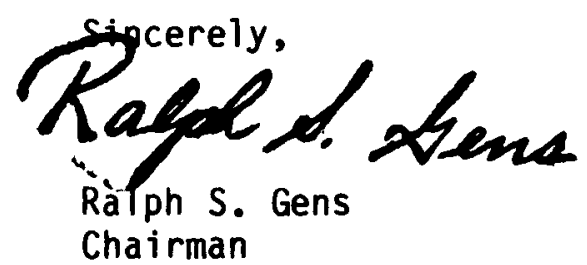




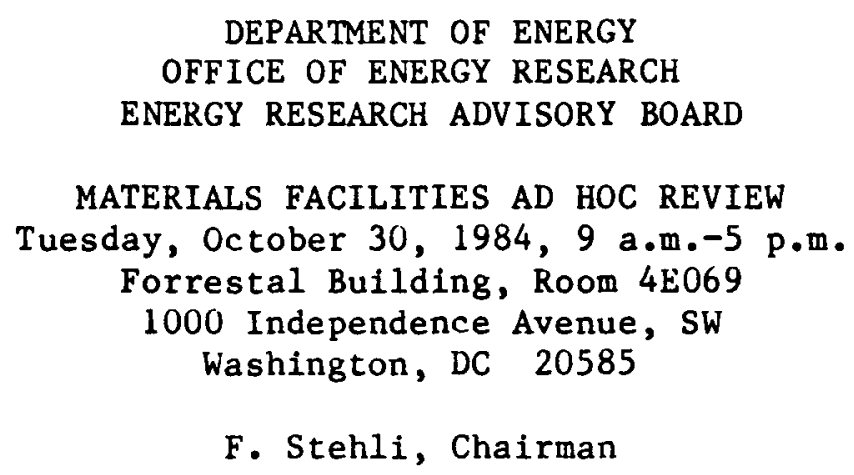

9:00 Opening Remarks

F. Stehli

9:05 Purpose of the Review

J. Snow

9:20 Synchrotron Radiation Priorities

D. Lynch

10:10 Coffee Break

10:30 Neutron Research Priorities

R. Brugger

11:20 "Other" Facilities Priorities

12:00 Lunch

1:15 The National Science Foundation view

M. Bardon

1:30 The Department of Defense view

L. Young

1:45 The Department of Commerce (NBS) view

D. Johnson

2:00 The Department of Energy (BES) view

R. Kropschot

2:15 Roundtable discussion of Agencies' views

2:40 Coffee Break

3:00 Review Committee Discussion

F. Steh11

- Other information needs

- Following meetings 


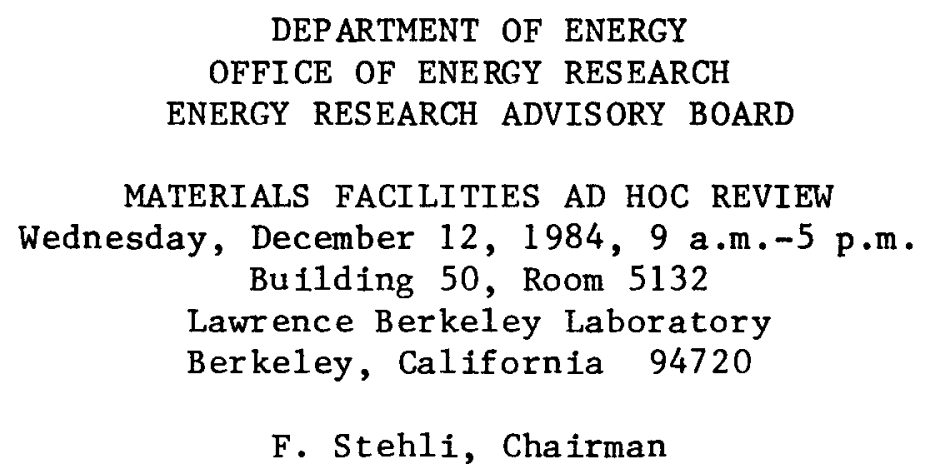

9:00 Opening Remarks, setting of next meeting

F. Stehl1

9:15 Synchrotron Radiation Prospect

M. Knotek

10:00 Coffee Break

10:15 Neutron Research Prospect

S. Werner

11:00 Discussion of NSF response to NRC study

Telex from

M. Bardon

11:30 DOE Management of Major Facilities

D. Stevens

$12: 00 \quad$ Lunch

$1: 15 \quad$ Stanford

A. Bienenstock

2:00 Lawrence Berkeley

D. Shirley

2:45 Lawrence Livermore

Kar1 Poppe

3:15 Coffee Break

3:30 Review Committee Discussion: Future agenda

F. Steh11 
The hajor BES User Facilities are those designed, constructed and operated to provite a unjque research capability in the United States; access to these facilities is provided to scientists conducting relevant research requiring the unique capabilities avallable. Many university and andustrial scientists are included anong the users.

The hajor BES User Facslities are:

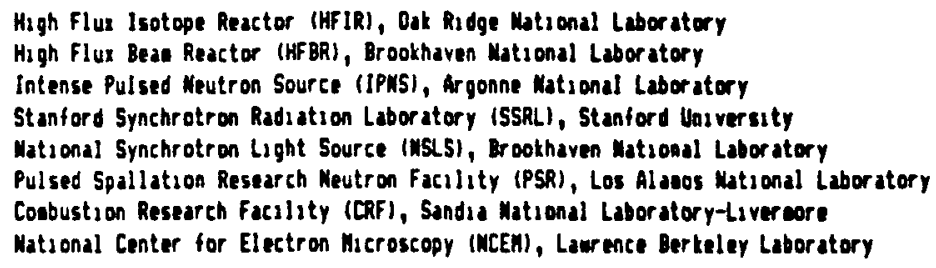

Mote: Funding figures are for FY1985 unless otherwse noted. They are based on the FY 1985 appropriation (A) and/or inforsation provided by the facilities (f) (Dollars in Thousands)

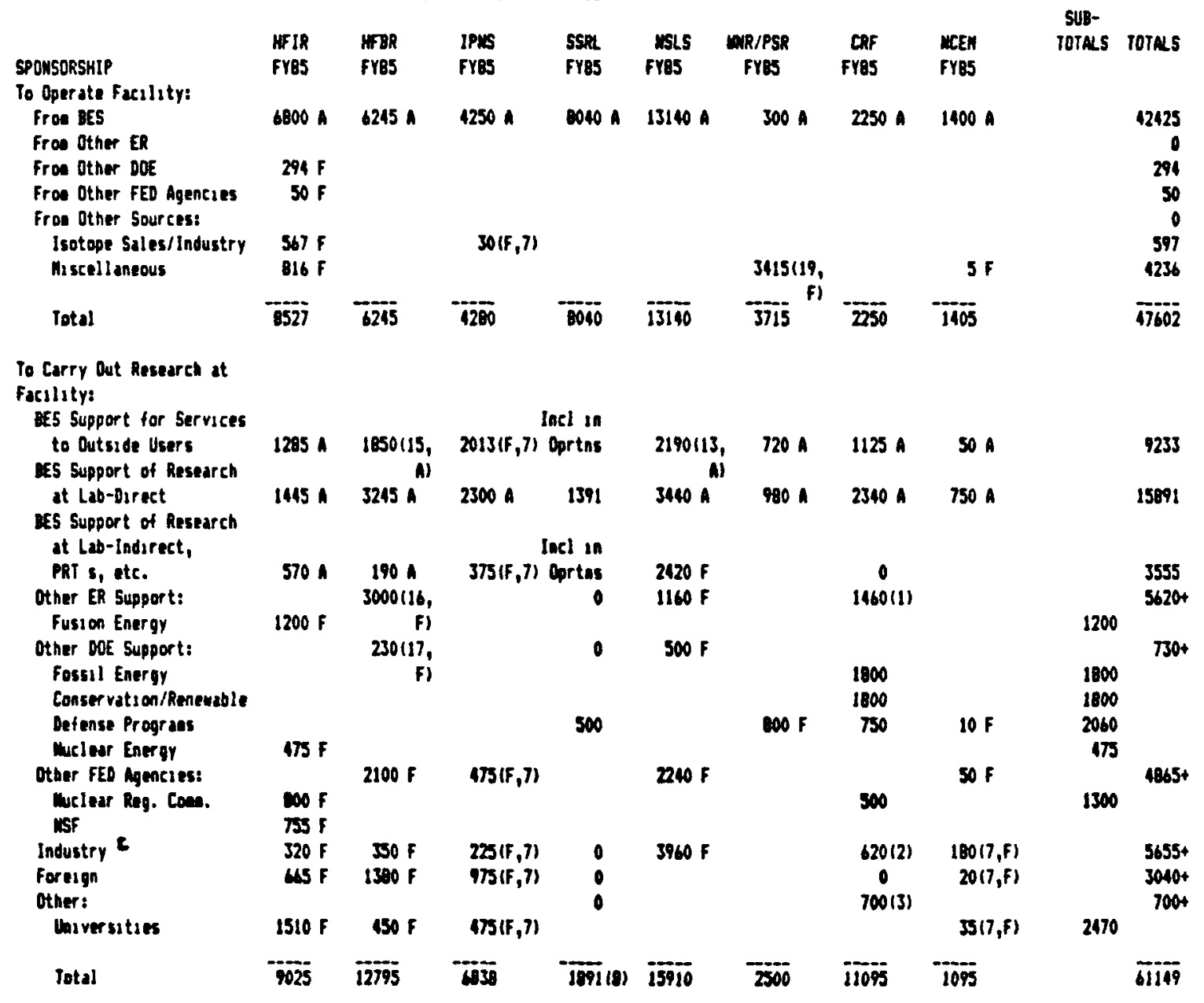




\begin{tabular}{|c|c|c|c|c|c|c|c|c|c|c|}
\hline & HFIR & HFBF & IFNS & SSFL & NSLL & SNR & CKF & NLEM & \multirow{2}{*}{\multicolumn{2}{|c|}{$\begin{array}{l}\text { TUTAL TOTALS } \\
\text { (PEOPLE) OVERALL }\end{array}$}} \\
\hline SFONSOKSHIP & FY85 & FY85 & FY85 & FY85 & fY85 & FYBS & FYB5 & FY851 & & \\
\hline DOE Labs - Sane Site & $21 \%$ & $17 \%$ & $33 \%$ & $2 \hbar$ & $25 \%$ & $25 \%$ & $60 \%$ & $30 \%$ & 267 & $18 \%$ \\
\hline DOE Labs - Other Sates & $6 \%$ & $5 \%$ & $5 \%$ & $14 \%$ & 84 & $12 \%$ & $2 \pi$ & $9 \%$ & 143 & $9 \%$ \\
\hline Other Governaent Labs & $2 x$ & $2 \%$ & 12 & $5 \%$ & & $6 \%$ & $3 \%$ & $2 \%$ & 52 & $3 \%$ \\
\hline Universities & 45\% & $50 \%$ & $30 \%$ & $41 \%$ & 42\% & $25 \%$ & $26 \%$ & $30 \%$ & 590 & $39 \%$ \\
\hline Industry & $9 \%$ & $5 \%$ & $6 \%$ & $25 \%$ & $20 \%$ & $7 x$ & $9 \%$ & $23 \%$ & 241 & $16 \%$ \\
\hline Foreign & $16 \%$ & $22 \%$ & $26 \%$ & $10 \%$ & $5 \%$ & $25 \%$ & $0 z$ & $6 \%$ & 208 & 14\% \\
\hline Dthers & - & - & - & 22 & - & & & & 15 & $1 \%$ \\
\hline Total & $100 \%$ & $100 \%$ & 1004 & $100 \%$ & 10011 & $1100 \%$ & 100 int & Juckis & 1517 & $100 \%$ \\
\hline iotal nunter of Users & 127 & 241 & 150 & 618 & 10 & 100 & 115 & 60 & & \\
\hline
\end{tabular}

A Data source is FY 85 Congressional Appropriations subprogran allotents

- Inforation on perforcers in thousands of dollars

(2) Includes $\$ 500 \mathrm{~K}$ for salary, travel, incidental costs for visiting scientists at CRF

(3) Estraated total travel, salary, incidental costs to universities, other labs for visiting scientists at CRF

(4) Officially involved experienters, includes SSRL research staff

(5) Performers are those who spend one week or longer at CRF; $Z$ is not of hY of effort;

BES sponsored resident staff accounts for about 35 I of KY of effort

(6) Based on 127 perforaers at HFIR in FY 1983; includes neutron scattering users only

(7) FY 84 experience

(8) FY 83 expersence

(12) Foreign users are teaporarlly affiliated with LBL and mork on DOE NCEN projects

(13) $\$ 1540 \mathrm{~K}$ of this is reported as "operations to support outsade users" at MSLS

(14) FYB4 experience with UV rang only; total of 146 users. This will rise with $x$-ray ring operations

(15) $\$ 145 \mathrm{~K}$ of this is reported as "operations to support outside users" at HFBR

(16) A significant percent of this is also for support to outside users at HFBR

(17) Estinated DOE support to University Users at HFBR

(19) Funds allocated internally to WMR/PSR froe several prograns (meapons progran, discretionary funds) 


\section{APPENDIX $F$}

\section{FACSIMILE}

DATE: $12 / 11 / 84$

ADDRESSEE'S NAME: Dr. F.G. Stehli, Chairman, ERAB

ADDRESSEE ORGANIZATION: Materials Facilities Ad Hoc Review Committee

STREET ADDRESS: Department of Energy

CITY, STATE, AND ZIP CODE: Washington, DC 20585

MESSAGE: Mr. Bloch has asked me to respond to your letter of November 30, 1984. I quite agree that the DOE and NSF need to assess their mutual roles in response to the NRC study, "Major Facilities for Materials Research and Related

Disciplines." I am therefore quite pleased that your ad hoc review committee is taking up this important issue at its meeting on December 12, 1984, at Lawrence Berkeley Laboratory.

What follows is our understanding of the current status of the response of other Federal agencies to this report and briefly gives NSF positions in each case.

MAJOR NEW FACILITIES

1. A $6 \mathrm{GeV}$-Synchrotron Radiation Facility. DOE has set up a subcommittee of the Energy Research Advisory Board (ERAB) to make recommendations regarding the DOE response. A conference has been held at Iowa State early in 0ctober 1984 to organize exploratory design and development for this facility.

NSF POSITION: This facility is needed by the U.S. The NSF will cooperate and coordinate with DOE in this initial, site-independent exploratory design and development phase.

2. An Advanced Steady State-Neutron Facility. Preliminary design studies are underway at Oak Ridge. It is not clear that such an improvement is feasible.

NSF POSITION: This activity falls within DOE's purview.

3. A 1 to-2-GeV Synchrotron Radiation Facility. DOE has a design completed and reviewed.

NSF POSITION: Contingent upon future of Alladin Project.

4. A-High Intensity Pulsed Neutron Facility. DOE does not feel that a case exists for such a facility. They will continue to fund facilities at Los Alamos and Argonne and monitor development of research that utilizes these facilities.

NSF POSITION: This activity falls within DOE's purview. 


\section{NEW CAPABILITIES AT EXISTING FACILITIES}

1. Centers for Cold Neutron Research

NBS is funded to install a cold source and to double reactor power to 20 megawatts; three experimental stations are planned (small-angle scattering, time-of-flight, depth profile analysis).

NBS will seek funding for a guide hall and a new building (approximately $\$ 25 \mathrm{M}$ over several years), which will permit 15 experimental stations, all to use cold neutrons.

Brookhaven will seek funding for a guide hall and a new building (approximately \$25M over several years, which will permit 15 experimental stations. Only five of these will use cold neutrons. Because of existing reactor design, the Brookhaven reactor will not produce a cold neutron flux superior to the NBS reactor even though it is a 60 megawatt reactor.

NSF POSITION: These activities fall within the purview of Commerce and DOE. From a scientific point of view, the Nation needs cold neutrons. Support for NBS is warranted.

2. Insertion Devices on Existing Synchrotron Radiation Facilities. DOE is proceeding with SSRL and NSLS.

NSF POSITION: Contingent on future of Aladdin Project.

3. Experimental Hall And Instrumentation at the Los Alamos National Laboratory.

DOE will build.

4. Upgrading of the National Magnet Laboratory. NSF responsibility. An experimental station that can produce 500 kilogauss for a millisecond is operational and being used for experiments. A properly instrumented user facility will be considered if scientific opportunities warrant it.

5. Enriched Pulsed Neutron Targets. DOE will provide material for these targets if proper safeguards can be maintained.

cc: Mr. Erich Bloch

SENDER'S NAME AND TITLE: Marcel Bardon, Acting Assistant Director for Mathematical and Physical Sciences

ORGANIZATION: National Science Foundation

PHONE AND ROOM NO. 357-9742 Room 512 


\section{CONTENTS}

I. EXECUTIVE SUMMARY $\ldots \ldots \ldots \ldots \ldots \ldots \ldots \ldots \ldots \ldots \ldots \ldots \ldots \ldots \ldots \ldots \ldots \ldots \ldots \ldots \ldots$

II. BACKGROUND AND CHARGES $\ldots \ldots \ldots \ldots \ldots \ldots \ldots \ldots \ldots \ldots \ldots \ldots \ldots \ldots \ldots \ldots$

III. REVIEW PROCEDURES AND CONSIDERATIONS $\ldots \ldots \ldots \ldots \ldots \ldots \ldots \ldots \ldots \ldots \ldots$

IV. FINDINGS, CONCLUSIONS AND RECOMMENDATIONS $\ldots \ldots \ldots \ldots \ldots \ldots \ldots \ldots \ldots$

v. FUNDING SCHEDULE $\ldots \ldots \ldots \ldots \ldots \ldots \ldots \ldots \ldots \ldots \ldots \ldots \ldots \ldots \ldots \ldots \ldots \ldots \ldots$

VI. REFERENCES AND BIBLIOGRAPHY $\ldots \ldots \ldots \ldots \ldots \ldots \ldots \ldots \ldots \ldots \ldots \ldots \ldots \ldots \ldots$

APPENDIX A, EXECUTIVE SUMMARY OF MAJOR MATERIALS FACILITIES REPORT.... A-1 APPENDIX B, SECRETARY'S CHARGE $\ldots \ldots \ldots \ldots \ldots \ldots \ldots \ldots \ldots \ldots \ldots \ldots \ldots \ldots \ldots$. . . . . .

APPENDIX $C$, ERAB CHAIRMAN'S CHARGE $\ldots \ldots \ldots \ldots \ldots \ldots \ldots \ldots \ldots \ldots \ldots \ldots \ldots \ldots \ldots$

APPENDIX D, REVIEW MEETINGS $\ldots \ldots \ldots \ldots \ldots \ldots \ldots \ldots \ldots \ldots \ldots \ldots \ldots \ldots \ldots \ldots \ldots$ D 1

APPENDIX E, MAJOR BASIC ENERGY SCIENCE FACILITY FUNDING AND USE,

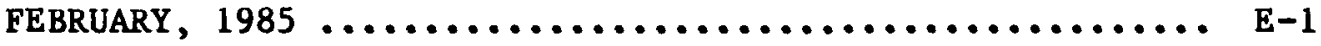

APPENDIX F, TELEX FROM THE NATIONAL SCIENCE FOUNDATION ........... F-1 
